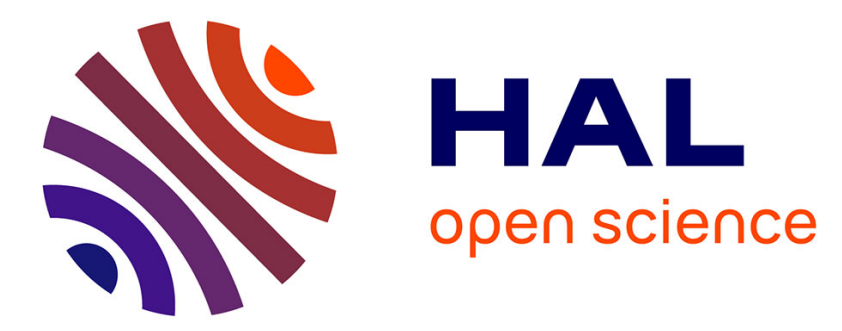

\title{
Near the Ferric Pseudobrookite Composition (Fe2TiO5).
}

Guillaume Seitz, Nicolas Penin, Léa Decoux, Alain Wattiaux, Mathieu

\author{
Duttine, Manuel Gaudon
}

\section{To cite this version:}

Guillaume Seitz, Nicolas Penin, Léa Decoux, Alain Wattiaux, Mathieu Duttine, et al.. Near the Ferric Pseudobrookite Composition (Fe2TiO5).. Inorganic Chemistry, 2016, 55 (5), pp.2499-2507. 10.1021/acs.inorgchem.5b02847 . hal-01285958

\section{HAL Id: hal-01285958 \\ https://hal.science/hal-01285958}

Submitted on 15 Jan 2021

HAL is a multi-disciplinary open access archive for the deposit and dissemination of scientific research documents, whether they are published or not. The documents may come from teaching and research institutions in France or abroad, or from public or private research centers.
L'archive ouverte pluridisciplinaire HAL, est destinée au dépôt et à la diffusion de documents scientifiques de niveau recherche, publiés ou non, émanant des établissements d'enseignement et de recherche français ou étrangers, des laboratoires publics ou privés. 


\title{
Near the ferric pseudobrookite composition $\left(\mathrm{Fe}_{2} \mathrm{TiO}_{5}\right)$.
}

\author{
Guillaume Seitz, Nicolas Penin, Léa Decoux, Alain Wattiaux, Mathieu Duttine and Manuel Gaudon* \\ Université de Bordeaux, CNRS, ICMCB, 87 Avenue du Dr. Albert Schweitzer, 33608 F-Pessac Cedex, France. \\ KEYWORDS. Pseudobrookite, Phase Diagram, X-Ray Diffraction, Pigment.
}

\begin{abstract}
Due to a very low thermodynamic stability, obtaining a pure monophasic compound of ferric pseudobrookite is quite difficult to achieve. Indeed, the low reticular energy of this phase leads easily to its decomposition and the occurrence of the secondary phases: hematite $\left(\mathrm{Fe}_{2} \mathrm{O}_{3}\right)$ and/or rutile $\left(\mathrm{TiO}_{2}\right)$. Samples with global composition $\mathrm{Fe}_{2-\mathrm{x}} \mathrm{Ti}_{1+\mathrm{x}} \mathrm{O}_{5}(\mathrm{x}=0,0.05$ and $0.10)$ have been synthesized by the Pechini route and thereafter, thermally treated at different temperatures. The concentration of $\mathrm{Fe}_{2} \mathrm{O}_{3}$ or $\mathrm{TiO}_{2}$ secondary phases were accurately determined and correlated with the target compositions and the synthesis parameters, especially the thermal treatment temperature. As revealed by Mössbauer spectroscopy, all iron ions are at the + III oxidation state. Thus, the formation of hematite or rutile as secondary phase may be related to the occurrence of cationic vacancies within the pseudobrookite structure, the amount of vacancies depending on the annealing temperature. In light of the presented results, it appears unreasonable to propose a "fixed" binary phase diagram for such a complex system. Furthermore, the occurrence of cationic vacancies induces a coloration change (darkening), preventing any industrial use of this reddish-brown pseudobrookite as ceramic pigment.
\end{abstract}

Introduction. Iron-titanium oxides with general formula (global composition) $\mathrm{Fe}_{2-\mathrm{x}} \mathrm{Ti}_{1+\mathrm{x}} \mathrm{O}_{5}$ (or $\mathrm{Fe}_{1+\mathrm{y}} \mathrm{Ti}_{2-\mathrm{y}} \mathrm{O}_{5}$ ) can have various chemical compositions ranging from $\mathrm{Fe}_{2} \mathrm{TiO}_{5}(\mathrm{x}=0)$, a ferric pseudobrookite, to $\mathrm{FeTi}_{2} \mathrm{O}_{5}(\mathrm{x}=1)$, a ferrous pseudobrookite. This oxide series is studied since the middle of the $20^{\text {th }}$ century. ${ }^{1-3}$

$\mathrm{Fe}_{2-\mathrm{x}} \mathrm{Ti}_{1+\mathrm{x}} \mathrm{O}_{5}$ pseudobrookite crystallizes with orthorhombic structure (space group $63 \mathrm{Cmcm}$ or equivalent), $\mathrm{Z}=4$, where the cations are located in two different octahedral sites, M1 and M2. ${ }^{4}$

${ }^{6}$ The structure (Figure 1) can be considered as compact with both M1 and M2 octahedra sharing edges with six other octahedra (M1 is linked to 3 M2 and 3 M1 and M2 is linked to six M1). Several models ${ }^{7-12}$ have been reported in literature concerning the $\mathrm{Fe}^{3+}$ and $\mathrm{Ti}^{4+}$ distribution in M1 (Wyckoff position: $4 c$ ) and M2 (8f) sites (see the review in which the long-term debate on the $\mathrm{Fe} / \mathrm{Ti}$ positioning is well summarized ${ }^{13}$ ). From Mössbauer and neutron diffraction results some researchers recently suggested that $\mathrm{Fe}^{3+}$ ions are slightly preferentially accommodated into M1 sites whereas $\mathrm{Ti}^{4+}$ ions have a slight preference for M2 sites. ${ }^{13}$ Whatever, the cationic distribution is pointed out to strongly depends on the preparation conditions and particle size. ${ }^{14-16}$ Over the past decades, numerous studies have focused on iron(III)-rich pseudobrookites considering their potential use as ferroelectromagnetic material in which both ferroelectric and magnetic ordering co-exist simultaneously, ${ }^{17-18}$ or considering their use as pigments but also their electrochemical or magnetic properties. ${ }^{19-21}$ Yellow-ochre to reddish-maroon or brown hues can be obtained by substituting iron or titanium ions with other metallic cations $\left(\right.$ e.g. $\left.\mathrm{Mg}^{2+}\right){ }^{22}$

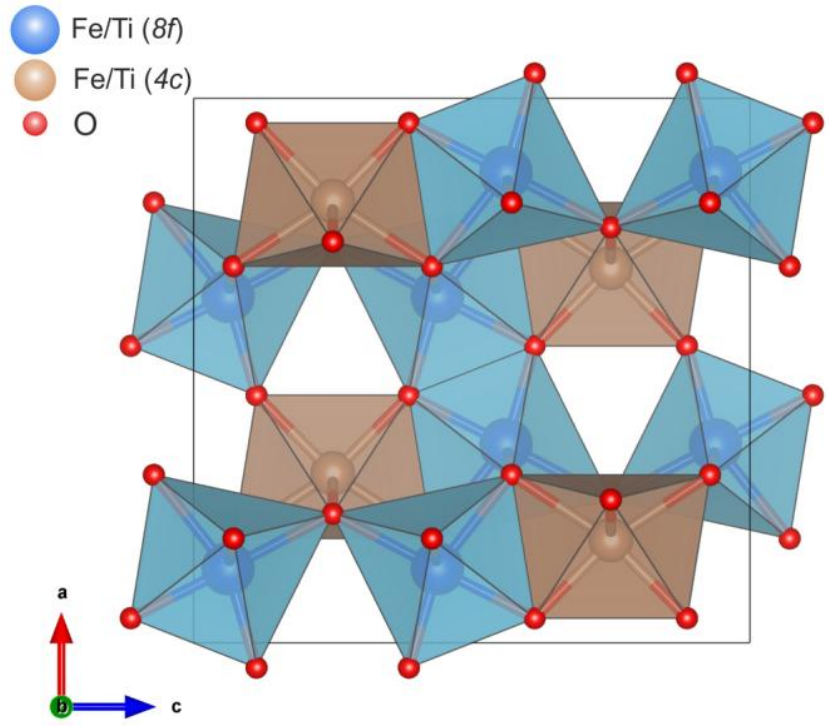

Figure 1: Representation of the pseudobrookite structure with projection along $b$ cell-axis. Drawing produced by VESTA ${ }^{\odot}{ }^{23}$

Pseudobrookite-based pigments were first developed in the seventies of the last century, ${ }^{19-20}$ in order to get heat-resistant colorants for thermoplastics, industrial paints and other applications involving low temperature treatments. ${ }^{22}$ Recently, Dondi et al. $^{21}$ have studied the potentialities of this type of compounds for ceramic pigment applications, i.e. application involving high temperature treatment. These pigments are commonly synthesized by solid state reaction with $\mathrm{TiO}_{2}$ (anatase) and $\mathrm{Fe}_{2} \mathrm{O}_{3}$ as precursors. The main issue of this synthesis route is, as reported in literature, "to achieve a complete reaction of the iron oxide". Hematite-free pseudobrookite is usually obtained adding a significant excess of titania in respect of the $\mathrm{Fe}_{2} \mathrm{TiO}_{5}$ stoichiometry. ${ }^{21,22}$ Several $\mathrm{TiO}_{2}-\mathrm{Fe}_{2} \mathrm{O}_{3}$ binary diagrams were reported in literature, in which the pseudobrookite is considered as the only stable solid solution between rutile $\left(\mathrm{TiO}_{2}\right)$ and hematite $\left(\alpha-\mathrm{Fe}_{2} \mathrm{O}_{3}\right)$. The stability domain is sharp and centered around $57 \mathrm{~mol} \%$ of $\mathrm{TiO}_{2}$. For Solid State chemists, it is quite difficult to understand why the $\mathrm{Fe}_{2} \mathrm{TiO}_{5}$ formula is not "stable" and why the only way to obtain a monophasic compound is to target an iron-deficient pseudobrookite. This phenomenon is probably related to the thermodynamic instability of this oxide. The stability of various pseudobrookite compounds were already analyzed using DTA runs and discussed in literature. ${ }^{24}$ It was concluded that the thermal expansion as well as the thermal stability (heat of formation) of $\mathrm{A}_{2} \mathrm{TiO}_{5}$ pseudobrookites (with $\mathrm{A}^{3+}$ ions $=\mathrm{Fe}^{3+}, \mathrm{Al}^{3+}, \mathrm{Ga}^{3+}$ ) is linked to the ionic radii of the cations 
present in the structure. Considering its positive enthalpy of formation $\left(8.3 \mathrm{~kJ} \mathrm{~mol}^{-1}\right)$, the iron-titanium compound should decompose at low temperature in a mixture of binary oxides. Nevertheless, the structure is stabilized by its configurational entropy of formation closely-related to partially-disordered cation distributions. ${ }^{25}$

Understanding the real stability of ferric-pseudobrookite is the challenge of this work. Our experiments have allowed us to evaluate the relative amount of hematite or rutile phases that is present beside the pseudobrookite main phase. The occurrence of the minor phases is directly correlated to the target composition and to the synthesis conditions through the thermodynamic rules governing the system. The optical properties of the synthesized compounds were also investigated and interrogated regarding their potential industrial use as ceramic pigments.

Experimental. The compounds were synthesized using the Pechini route. ${ }^{26-28}$ This chemical process is based on cations chelation by citric acid (CA) and on polyesterification between $\mathrm{CA}$ and ethylene glycol (EG) which leads to the formation of a polycationic resin. Aqueous solutions of citrate were prepared by dissolving $\mathrm{CA}$ in a minimal volume of water. Then, cationic salts: $\mathrm{Fe}\left(\mathrm{NO}_{3}\right)_{3} 6 \mathrm{H}_{2} \mathrm{O}$ and $\mathrm{TiOCl}_{2}$ were added in stoichiometric proportion to the acid solution. Three target compositions close to the theoretical "ferric" $\mathrm{Fe}_{2} \mathrm{TiO}_{5}$ composition were prepared: $\mathrm{Fe}_{2} \mathrm{TiO}_{5}, \mathrm{Fe}_{1.95} \mathrm{Ti}_{1.05} \mathrm{O}_{5}$ and $\mathrm{Fe}_{1.90} \mathrm{Ti}_{1.10} \mathrm{O}_{5}$ (denoted S1, S2 and S3, respectively). A CA/cations molar ratio equal to $3 / 1$ was used. After complete dissolution of the metallic salts, EG was added with a 4/1 EG/CA molar ratio. EG-CA polymerization was promoted by removing water with continuous heating on a hot plate. Then, a two-step thermal treatment was applied to the highly viscous mixtures: first, a calcination at $300^{\circ} \mathrm{C}$ for $10 \mathrm{~h}$ and then, an annealing dwell for $20 \mathrm{~h}$ at two temperatures $900^{\circ} \mathrm{C}$ or $1400^{\circ} \mathrm{C}$ (denoted A and B, respectively). All thermal treatments were performed in air and at ambient pressure. Hence, 6 compounds will be herein discussed and accurately characterized: S1A, S1B, S2A, S2B, S3A and S3B samples.

$\mathrm{X}$-Ray Diffraction (XRD) measurements were carried out on a PANalytical X'PERT PRO diffractometer equipped with a Xcelerator detector, using $\mathrm{Cu}-\mathrm{K} \alpha_{1}$ radiation. The structural parameters (unit cell parameters, atomic positions and occupancies and Debye Weller factors) were refined using the Rietveld method, ${ }^{29-30}$ and the Fullprof $®$ program package. All the patterns were analyzed using the Caglioti function, i.e. the isotropic peak profile function for which the $\mathrm{u}, \mathrm{v}, \mathrm{w}$ and shape parameters are refined.

Morphological and microstructural characterizations were performed, at PLACAMAT (UMS-3626, Pessac, France), on a Scanning Electron Microscope with Field Emission Gun (FEGSEM) JEOL JSM 6700F, operating in secondary electrons mode with a $10 \mathrm{kV}$ accelerating voltage.

Mössbauer spectra were recorded in transmission geometry using a constant acceleration Halder-type spectrometer with a room temperature ${ }^{57} \mathrm{Co}$ source ( $\mathrm{Rh}$ matrix). The velocity scale was calibrated using a pure metal iron foil and isomer shift values are then expressed with respect to $\alpha-\mathrm{Fe}^{0}$ at room temperature. The polycrystalline absorbers containing about $10 \mathrm{mg} / \mathrm{cm}^{2}$ of iron were placed into a cryostat (liquid $\mathrm{He}$ ) in order to collect ${ }^{57} \mathrm{Fe}$ Mössbauer spectra at various temperatures, from $293 \mathrm{~K}$ down to $4.2 \mathrm{~K}$. Refinement of the Mössbauer hyperfine parameters $(\delta$ isomer shift, $\Delta$ quadrupole splitting, $\varepsilon$ quadrupole shift, $H$ hyperfine field, $\Gamma$ signal linewidth and relative areas) was performed using homemade programs and the WinNormos ${ }^{\circledR}$ software.
Diffuse absorption spectra were recorded at room temperature from 200 to $800 \mathrm{~nm}$ on a Cary 17 spectrophotometer using an integration sphere (spectral resolution: $1 \mathrm{~nm}$ and band length: $2 \mathrm{~nm}$ ). Halon was used as white reference. RGB space colorimetric parameters were determined from the spectra using a two-step mathematic treatment. The first step consists in extracting the XYZ tri-stimulus values (defined by the CIE, 1964) from the integration (over the visible range, i.e. from $\lambda=380 \mathrm{~nm}$ up to $780 \mathrm{~nm}$ ) of the product of $\mathrm{x}(\lambda), \mathrm{y}(\lambda)$ or $\mathrm{z}(\lambda)$ functions (CIE - 1964) with the diffuse reflectance spectra function $X=\int x(\lambda) \cdot R(\lambda) d \lambda$. Then, the transfer equations defined by the CIE, 1976, from XYZ space to RGB space, were used in order to obtain the RGB chromatic parameters. Instead of the commonly used three-color space parameters $\left(\mathrm{L}^{*}, \mathrm{a}^{*}\right.$ and $\left.\mathrm{b}^{*}\right)$, we will report thereafter the RGB parameters in order to allow anyone reproducing the right coloration with commonly available drawing software (or, for example, Microsoft Powerpoint ${ }^{\circledR}$ ).

Results and discussion. Prior to any further characterization, all synthesized compounds were analyzed by X-ray diffraction. Among all samples annealed at $900^{\circ} \mathrm{C}$, a pure pseudobrookite phase was only obtained for the S2 composition, whereas hematite or rutile secondary phase is detected for the S1A or S3A sample, respectively. After a thermal treatment at $1400^{\circ} \mathrm{C}$, the pure pseudobrookite phase is obtained for the S3 composition, whereas the S1B and S2B samples contain different amounts of hematite. The refinements are illustrated in the Figures 2 and 3, respectively for the $900^{\circ} \mathrm{C}$-samples and $1400^{\circ} \mathrm{C}$-samples; when two phases are needed for the refinement, the impurity' Bragg positions are reported on the bottom line. The correlation parameters are reported in Table 1, the unit cell parameters of each phase determined from Rietveld analysis are reported in Table 2 and the atomic positions in Tables $3 \& 4$. The structural parameters of the main pseudobrookite phase were refined on the basis of $C \mathrm{cmm}$ space group.

TABLE 1. Correlation factors for the main phase of the various analyzed samples (Figures 2 and 3).

\begin{tabular}{|cccccc|}
\hline Sample & micro-abs. & Rp & Rwp & Rexp & RBragg \\
\hline S1A & $9(5)$ & 0.206 & 0.134 & 0.105 & 0.055 \\
S2A & $9(5)$ & 0.190 & 0.125 & 0.096 & 0.058 \\
S3A & $18(5)$ & 0.205 & 0.131 & 0.099 & 0.067 \\
\hline S1B & 0 & 0.281 & 0.172 & 0.108 & 0.126 \\
S2B & $30(8)$ & 0.319 & 0.212 & 0.133 & 0.133 \\
S3B & 22(7) & 0.275 & 0.166 & 0.123 & 0.102 \\
\hline
\end{tabular}

TABLE 2. Unit cell parameters determined from Rietveld analysis of XRD powder patterns of samples annealed at $900^{\circ} \mathrm{C}(\mathrm{SxA})$ or $1400^{\circ} \mathrm{C}(\mathrm{SxB})$.

\begin{tabular}{|c|c|c|c|c|c|c|}
\hline \multirow{2}{*}{\multicolumn{2}{|c|}{\begin{tabular}{|l} 
Sample S1A \\
Phase I Fe $\mathrm{Fe}_{2-\mathrm{x}} \mathrm{Ti}_{1+\mathrm{x}} \mathrm{O}$
\end{tabular}}} & \multirow{2}{*}{$\frac{\mathrm{S} 2 \mathrm{~A}}{5_{5}}$} & \multirow[t]{2}{*}{$\mathrm{S} 3 \mathrm{~A}$} & \multirow[t]{2}{*}{ S1B } & \multirow[t]{2}{*}{$\mathrm{S} 2 \mathrm{~B}$} & \multirow[t]{2}{*}{$\mathrm{S} 3 \mathrm{~B}$} \\
\hline & & & & & & \\
\hline a $(\hat{A})$ & $9.7905(4)$ & $9.7898(4)$ & $9.7907(4)$ & $9.7825(2)$ & $9.7808(3)$ & $9.7768(2)$ \\
\hline b (Ả) & $3.7264(2)$ & $3.7261(2)$ & $3.7252(2)$ & $3.7311(1)$ & $3.7312(1)$ & $3.7322(1)$ \\
\hline c $(\AA ̉)$ & $9.9797(4)$ & $9.9816(4)$ & $9.9842(4)$ & $9.9738(2)$ & $9.9733(3)$ & $9.9707(2)$ \\
\hline $\mathrm{V}\left(\AA^{3}\right)$ & $364.10(3)$ & $364.11(3)$ & $364.14(3)$ & $364.03(1)$ & $363.97(2)$ & $363.82(2)$ \\
\hline \multicolumn{2}{|c|}{ Phase $\mathrm{IIFe}_{2} \mathrm{O}_{3}$} & & $\mathrm{TiO}_{2}$ & $\mathrm{Fe}_{2} \mathrm{O}_{3}$ & $\mathrm{Fe}_{2} \mathrm{O}_{3}$ & \\
\hline a (Ả) & $5.0363(3)$ & & $4.5934(4)$ & $5.0332(5)$ & $5.034(1)$ & \\
\hline $\mathrm{b}(\mathrm{A})$ & $5.0363(3)$ & & $4.5934(4)$ & $5.0332(2)$ & $5.034(1)$ & \\
\hline c $(\AA)$ & $13.749(1)$ & & $2.9597(4)$ & $13.753(1)$ & $13.753(4)$ & \\
\hline $\mathrm{V}\left(\AA^{3}\right)$ & $302.00(3)$ & & $62.45(2)$ & $301.72(2)$ & $301.8(2)$ & \\
\hline
\end{tabular}


The structural refinements, using the Rietveld method, provide good fits of the XRD data, especially for the $900^{\circ} \mathrm{C}$ samples with RBragg factors lower than $6 \%$ (Table 1). The $1400^{\circ} \mathrm{C}$ samples exhibit higher correlation factors due to a slight mismatch of some experimental and calculated peaks (shape and intensity). This cannot be related to preferential orientations since the various peaks, whose intensity is not well described, are not linked by crystallographic orientations. Indeed, the simulation of these diffraction patterns using an anisotropic peak profile function (able to take into account some crystallite anisotropic shape) did not improve anyway the refinement quality. Moreover, for the $\mathrm{SxB}$ samples, the linewidth of the diffraction peaks is quite low and can be related to very large crystallite sizes.

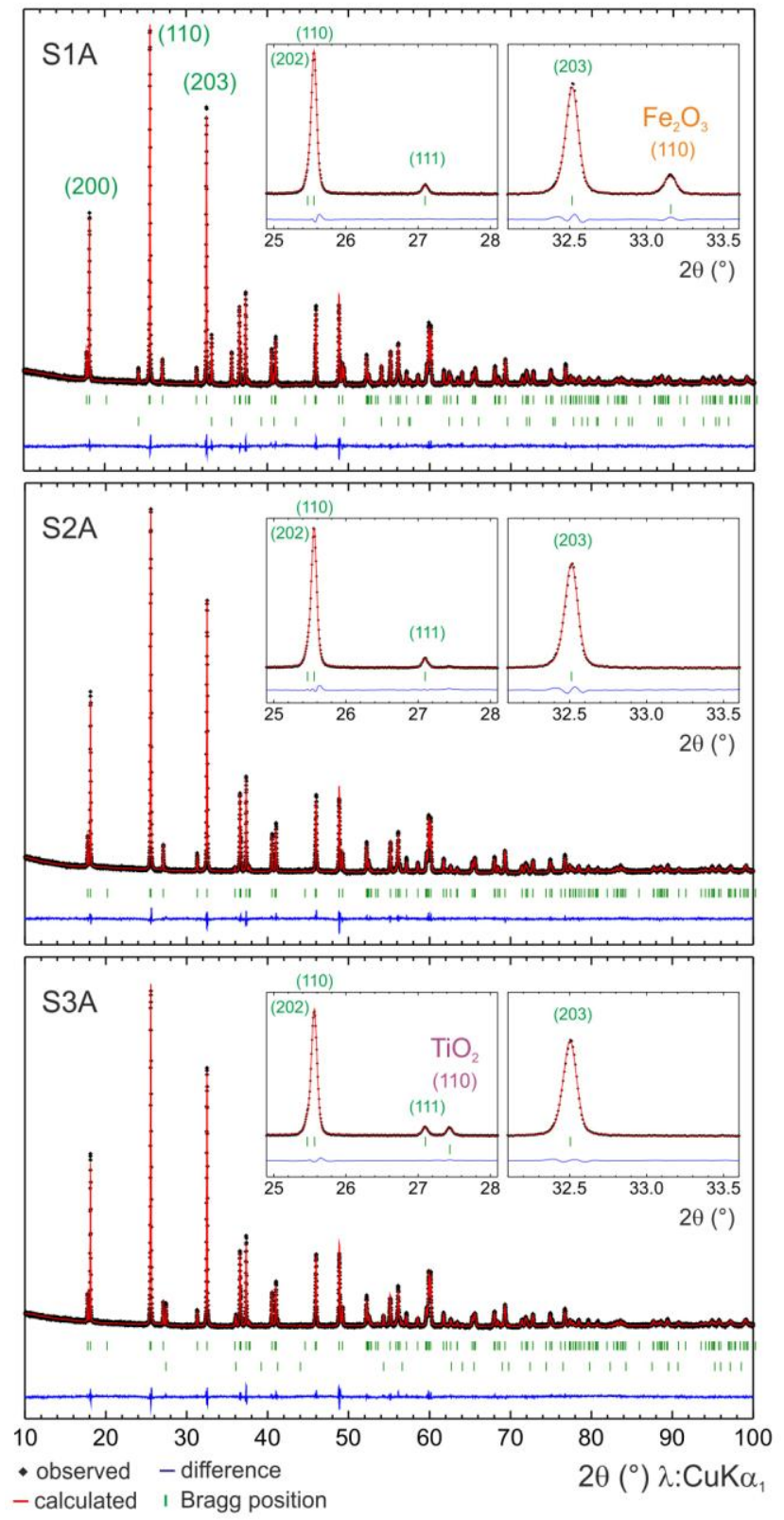

Figure 2: Rietveld analyses of $\left(\mathrm{Cu} \mathrm{K} \alpha_{1}\right) \mathrm{X}$-ray diffraction powder patterns of SxA compounds (annealed at $900^{\circ} \mathrm{C}$ ). Refined cell parameters and atomic positions are reported in Table 2 and 3.
Thus, the number of analyzed crystallites being actually lower, the XRD descriptive statistics are clearly worse, leading to higher reliability factors ( $\mathrm{R}_{\text {Bragg: }}$ 10-13\%). Furthermore, all isotropic displacement factors are slightly negative and rather low (in absolute value) despite the corrections for micro-absorption effects due to iron fluorescence over copper X-ray radiations. Nevertheless, the refinement of structural parameters brought some interesting results. First of all, the chemical composition of the main phase was considered to be $\mathrm{Fe}_{1.95} \mathrm{Ti}_{1.05} \mathrm{O}_{5}$ for the three SxA samples and $\mathrm{Fe}_{1.90} \mathrm{Ti}_{1.10} \mathrm{O}_{5}$ for the three $\mathrm{SxB}$ samples (only S2A and S3B samples are monophasic). Then, the structural refinements were conducted considering a distribution of $\mathrm{Fe}^{3+}$ and $\mathrm{Ti}^{4+}$ ions in $4 c$ and $8 f$ sites with respect to these main phase compositions.

TABLE 3. Rietveld refinement results for the samples obtained at $900^{\circ} \mathrm{C}$.

\begin{tabular}{|c|c|c|c|c|c|c|}
\hline Atom & Site & $\mathrm{x}$ & $\mathrm{y}$ & $\mathrm{z}$ & Occ. & $\mathrm{B}\left(\AA^{2}\right)$ \\
\hline \multicolumn{7}{|l|}{ S1A } \\
\hline \multicolumn{7}{|c|}{$\mathrm{Fe}_{1.95} \mathrm{Ti}_{1.05} \mathrm{O}_{5}(\mathrm{Cmcm})$} \\
\hline $\mathrm{Fe} 1$ & $4 c$ & $0.813(1)$ & 0 & $1 / 4$ & $0.20(1)$ & $-0.1(2)$ \\
\hline Ti1 & $4 c$ & $0.813(1)$ & 0 & $1 / 4$ & $0.04(1)$ & $-0.1(2)$ \\
\hline $\mathrm{Fe} 2$ & $8 f$ & $0.137(1)$ & 0 & $0.064(1)$ & $0.28(1)$ & $-0.4(1)$ \\
\hline Ti2 & $8 f$ & $0.137(1)$ & 0 & $0.064(1)$ & $0.22(1)$ & $-0.4(1)$ \\
\hline $\mathrm{O} 1$ & $4 c$ & $0.236(1)$ & 0 & $1 / 4$ & $1 / 4$ & $-0.4(2)$ \\
\hline $\mathrm{O} 2$ & $8 f$ & $0.046(1)$ & 0 & $0.883(1)$ & $1 / 2$ & $-0.4(2)$ \\
\hline $\mathrm{O} 3$ & $8 f$ & $0.311(1)$ & 0 & $0.927(1)$ & $1 / 2$ & $-0.4(2)$ \\
\hline \multicolumn{7}{|c|}{$\mathrm{Fe}_{2} \mathrm{O}_{3} \quad(R-3 c)$} \\
\hline $\mathrm{Fe}$ & $12 \mathrm{c}$ & 0 & 0 & $0.355(1)$ & $1 / 3$ & 1 \\
\hline $\mathrm{O}$ & $18 \mathrm{e}$ & $0.306(4)$ & 0 & $1 / 4$ & $1 / 2$ & 1 \\
\hline \multicolumn{7}{|l|}{$\mathrm{S} 2 \mathrm{~A}$} \\
\hline \multicolumn{7}{|c|}{$\mathrm{Fe}_{1.95} \mathrm{Ti}_{1.05} \mathrm{O}_{5}(\mathrm{Cmcm})$} \\
\hline $\mathrm{Fe} 1$ & $4 c$ & $0.813(1)$ & 0 & $1 / 4$ & $0.19(1)$ & $-0.1(2)$ \\
\hline Ti1 & $4 c$ & $0.813(1)$ & 0 & $1 / 4$ & $0.06(1)$ & $-0.1(2)$ \\
\hline $\mathrm{Fe} 2$ & $8 \mathrm{f}$ & $0.136(1)$ & 0 & $0.064(1)$ & $0.30(1)$ & $0.1(1)$ \\
\hline Ti2 & $8 \mathrm{f}$ & $0.136(1)$ & 0 & $0.064(1)$ & $0.20(1)$ & $0.1(1)$ \\
\hline O1 & $4 c$ & $0.242(1)$ & 0 & $1 / 4$ & $1 / 4$ & $-0.2(2)$ \\
\hline $\mathrm{O} 2$ & $8 \mathrm{f}$ & $0.048(1)$ & 0 & $0.883(1)$ & $1 / 2$ & $-0.2(2)$ \\
\hline $\mathrm{O} 3$ & $8 \mathrm{f}$ & $0.310(1)$ & 0 & $0.929(1)$ & $1 / 2$ & $-0.2(2)$ \\
\hline \multicolumn{7}{|l|}{ S3A } \\
\hline \multicolumn{7}{|c|}{$\mathrm{Fe}_{1.95} \mathrm{Ti}_{1.05} \mathrm{O}_{5}(\mathrm{Cmcm})$} \\
\hline $\mathrm{Fe} 1$ & $4 c$ & $0.813(1)$ & 0 & $1 / 4$ & $0.20(1)$ & $0.1(2)$ \\
\hline Ti1 & $4 c$ & $0.813(1)$ & 0 & $1 / 4$ & $0.04(1)$ & $0.1(2)$ \\
\hline $\mathrm{Fe} 2$ & $8 \mathrm{f}$ & $0.136(1)$ & 0 & $0.064(1)$ & $0.28(1)$ & $-0.1(1)$ \\
\hline Ti2 & $8 \mathrm{f}$ & $0.136(1)$ & 0 & $0.064(1)$ & $0.22(1)$ & $-0.1(1)$ \\
\hline O1 & $4 c$ & $0.241(1)$ & 0 & $1 / 4$ & $1 / 4$ & $0.0(2)$ \\
\hline $\mathrm{O} 2$ & $8 \mathrm{f}$ & $0.047(1)$ & 0 & $0.883(1)$ & $1 / 2$ & $0.0(2)$ \\
\hline $\mathrm{O} 3$ & $8 \mathrm{f}$ & $0.310(1)$ & 0 & $0.927(1)$ & $1 / 2$ & $0.0(2)$ \\
\hline \multicolumn{7}{|c|}{$\mathrm{TiO}_{2}(P 42 / m n m)$} \\
\hline $\mathrm{Ti}$ & $2 a$ & 0 & 0 & 0 & $1 / 8$ & 1 \\
\hline $\mathrm{O}$ & $4 \mathrm{f}$ & $0.30(1)$ & $0.30(1)$ & 0 & $1 / 4$ & 1 \\
\hline
\end{tabular}

The occupancy rate of each cation at these two Wyckoff positions was refined. A slight preferential distribution of iron species in the M1 (4c) site and, in correlation, a preferential distribution of $\mathrm{Ti}^{4+}$ ion in the M2 $(8 f)$ site was then evidenced. Indeed, the molar 
percentages of iron ions located at the $8 f$ and $4 c$ sites are 60-65 $\mathrm{mol} \%$ and $35-40 \mathrm{~mol} \%$, respectively, what is slightly different from the expected random distribution of iron ions across the two sites M2 and M1 (66.7 and $33.3 \mathrm{~mol} \%$, respectively).

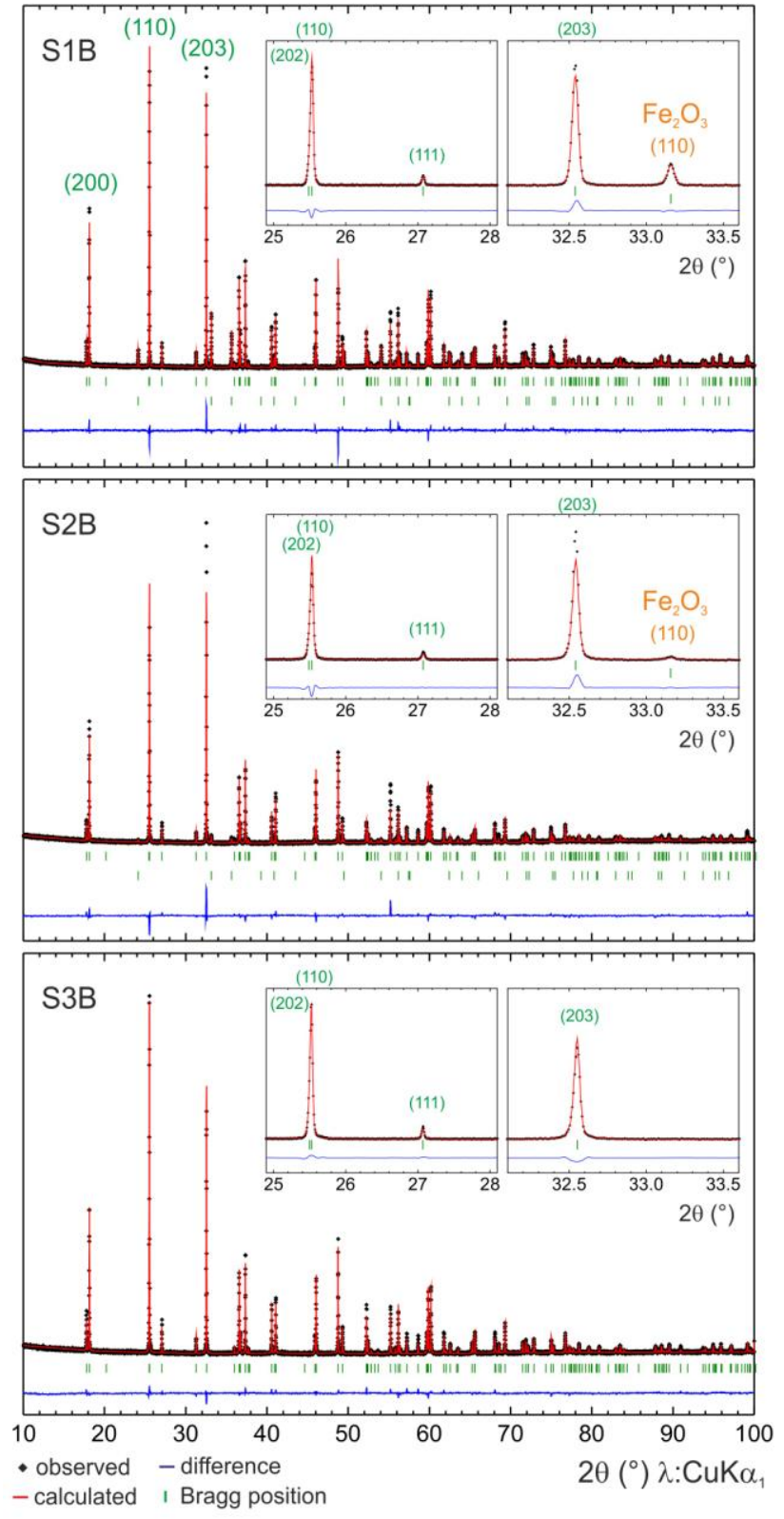

Figure 3: Rietveld analyses of $\left(\mathrm{Cu} \mathrm{K} \alpha_{1}\right)$ X-ray diffraction powder patterns of SxB compounds (annealed at $1400^{\circ} \mathrm{C}$ ). Refined cell parameters and atomic positions are reported in Table 2 and 4.

The cell parameters of the main phase do not significantly vary from a sample to another, within each group (SA or SB, see Table 2). This observation confirms that the main phase exhibits one same composition whatever the initial global composition of the samples. Actually, $a, b$ and $c$ cell parameters can clearly be split up into two series of values: one for the A samples and another for the B samples (Table 2). Thus, the main phase composition seems to be influenced by the thermal treatment and absolutely not by the initial $\mathrm{Fe} / \mathrm{Ti}$ ratio inside the raw powder. The corollary of this is the formation of secondary phases due to the mismatch between the main phase composition and the initial $\mathrm{Fe} / \mathrm{Ti}$ ratio.

TABLE 4. Rietveld refinement results for the samples obtained at $1400^{\circ} \mathrm{C}$.

\begin{tabular}{|c|c|c|c|c|c|c|}
\hline Atom & Site & $\mathrm{x}$ & $\mathrm{y}$ & $\mathrm{z}$ & Occ. & $\mathrm{B}\left(\AA^{2}\right)$ \\
\hline \multicolumn{7}{|l|}{ S1B } \\
\hline \multicolumn{7}{|c|}{$\mathrm{Fe}_{1.90} \mathrm{Ti}_{1.10} \mathrm{O}_{5}(\mathrm{Cmcm})$} \\
\hline $\mathrm{Fe} 1$ & $4 c$ & $0.812(1)$ & 0 & $1 / 4$ & $0.18(2)$ & $-0.1(2)$ \\
\hline Ti1 & $4 \mathrm{c}$ & $0.812(1)$ & 0 & $1 / 4$ & $0.07(2)$ & $-0.1(2)$ \\
\hline $\mathrm{Fe} 2$ & $8 \mathrm{f}$ & $0.137(1)$ & 0 & $0.064(1)$ & $0.30(2)$ & $-0.6(2)$ \\
\hline Ti2 & $8 \mathrm{f}$ & $0.137(1)$ & 0 & $0.064(1)$ & $0.20(2)$ & $-0.6(2)$ \\
\hline O1 & $4 c$ & $0.241(2)$ & 0 & $1 / 4$ & $1 / 4$ & $0.0(2)$ \\
\hline $\mathrm{O} 2$ & $8 \mathrm{f}$ & $0.051(2)$ & 0 & $0.885(1)$ & $1 / 2$ & $0.0(2)$ \\
\hline $\mathrm{O} 3$ & $8 \mathrm{f}$ & $0.315(2)$ & 0 & $0.927(2)$ & $1 / 2$ & $0.0(2)$ \\
\hline \multicolumn{7}{|c|}{$\mathrm{Fe}_{2} \mathrm{O}_{3}(R-3 c)$} \\
\hline $\mathrm{Fe}$ & $12 \mathrm{c}$ & 0 & 0 & $0.355(1)$ & $1 / 3$ & 1 \\
\hline $\mathrm{O}$ & $18 \mathrm{e}$ & $0.692(5)$ & 0 & $1 / 4$ & $1 / 2$ & 1 \\
\hline \multicolumn{7}{|l|}{ S2B } \\
\hline \multicolumn{7}{|c|}{$\mathrm{Fe}_{1.90} \mathrm{Ti}_{1.10} \mathrm{O}_{5}(\mathrm{Cmcm})$} \\
\hline $\mathrm{Fe} 1$ & $4 c$ & $0.811(1)$ & 0 & $1 / 4$ & $0.15(2)$ & $-0.3(3)$ \\
\hline Ti1 & $4 c$ & $0.811(1)$ & 0 & $1 / 4$ & $0.10(2)$ & $-0.3(3)$ \\
\hline $\mathrm{Fe} 2$ & $8 f$ & $0.137(1)$ & 0 & $0.066(1)$ & $0.33(2)$ & $-0.5(2)$ \\
\hline Ti2 & $8 \mathrm{f}$ & $0.137(1)$ & 0 & $0.066(1)$ & $0.18(2)$ & $-0.5(2)$ \\
\hline O1 & $4 \mathrm{c}$ & $0.251(1)$ & 0 & $1 / 4$ & 0.25 & $-0.2(2)$ \\
\hline $\mathrm{O} 2$ & $8 \mathrm{f}$ & $0.047(1)$ & 0 & $0.881(2)$ & 0.50 & $-0.2(2)$ \\
\hline $\mathrm{O} 3$ & $8 \mathrm{f}$ & $0.310(1)$ & 0 & $0.927(2)$ & 0.50 & $-0.2(2)$ \\
\hline \multicolumn{7}{|c|}{$\mathrm{Fe}_{2} \mathrm{O}_{3} \quad(R-3 c)$} \\
\hline $\mathrm{Fe}$ & $12 \mathrm{c}$ & 0 & 0 & $0.353(3)$ & $1 / 3$ & 1 \\
\hline $\mathrm{O}$ & $18 \mathrm{e}$ & $0.68(3)$ & 0 & $1 / 4$ & $1 / 2$ & 1 \\
\hline \multicolumn{7}{|l|}{ S3B } \\
\hline \multicolumn{7}{|c|}{$\mathrm{Fe}_{1.90} \mathrm{Ti}_{1.10} \mathrm{O}_{5}(\mathrm{Cmcm})$} \\
\hline $\mathrm{Fe} 1$ & $4 c$ & $0.811(1)$ & 0 & $1 / 4$ & $0.21(2)$ & $-0.1(2)$ \\
\hline Ti1 & $4 c$ & $0.811(1)$ & 0 & $1 / 4$ & $0.04(2)$ & $-0.1(2)$ \\
\hline $\mathrm{Fe} 2$ & $8 \mathrm{f}$ & $0.136(1)$ & 0 & $0.062(1)$ & $0.27(2)$ & $-0.3(2)$ \\
\hline Ti2 & $8 \mathrm{f}$ & $0.136(1)$ & 0 & $0.062(1)$ & $0.23(2)$ & $-0.3(2)$ \\
\hline O1 & $4 \mathrm{c}$ & $0.237(2)$ & 0 & $1 / 4$ & $1 / 4$ & $-0.2(2)$ \\
\hline $\mathrm{O} 2$ & $8 \mathrm{f}$ & $0.045(1)$ & 0 & $0.887(1)$ & $1 / 2$ & $-0.2(2)$ \\
\hline $\mathrm{O} 3$ & $8 \mathrm{f}$ & $0.308(1)$ & 0 & $0.928(1)$ & $1 / 2$ & $-0.2(2)$ \\
\hline
\end{tabular}

To complete the study, SEM-FEG observations were performed on the various synthesized samples. As illustration, SEM photographs of the S2A and S2B samples are presented by Figure 4. All the A-samples show a grain size distribution centered at about $200 \mathrm{~nm}$ whereas the B-samples grain sizes mainly range from 10 to $20 \mu \mathrm{m}$ (particle diameter). It can be noted that the grain sizes obtained from microscopy are in good agreement with the X-ray peak width and for the SxB samples the grains exhibit a faceted morphology; hence, we could assume that the observed grains are monocrystalline (i.e. corresponding to the crystalline domains). This observation shows that the degree of crystalline growth due to sintering is extremely different for the SxA and 
SxB samples. The second phase (hematite) detected by X-ray diffraction for the S2B sample was not evidenced by electron microscopy; this lack of the hematite observation can be explained by the very minor character of this phase.

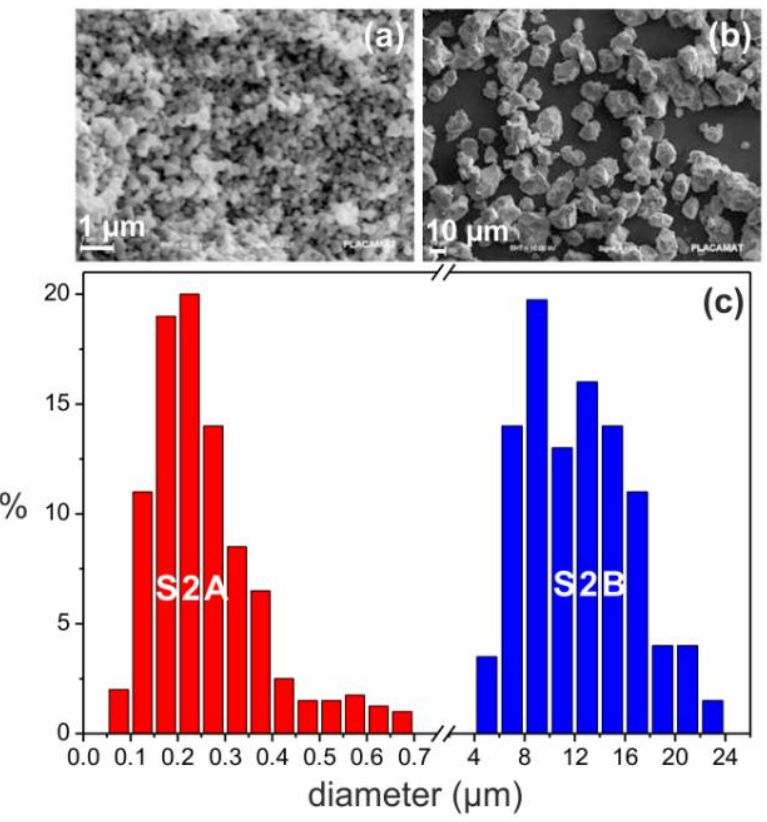

Figure 4: SEM-FEG micrographs of (a) S2A and (b) S2B samples and (c) associated grain size distributions.

These experiments have shown that the occurrence or not of impurities besides the pseudobrookite phase depends on two factors: the raw sample composition and the synthesis conditions. Indeed, the global composition leading to the obtaining of a monophasic pseudobrookite is not the same for the two tested thermal treatments. However, for a same thermal treatment performed on different initial compositions, the chemical composition of the pseudobrookite is the same, the formation of a secondary phase (hematite or rutile) resulting hence from the difference between the chemical composition of the main phase obtained and the raw sample composition. To prove this hypothesis, the plotting of the second phase concentration for A and $\mathrm{B}$ samples versus the raw sample composition ( $\mathrm{x}$ composition parameter) is reported in the Figure 5. The plot corroborates the obtaining of a single composition for the main pseudobrookite phase whatever the global sample composition and only depending on the thermal treatment. Indeed, the quantity of $\mathrm{Fe}_{2} \mathrm{O}_{3}$ or $\mathrm{TiO}_{2}$ secondary phase is directly proportional to the excess of the $\mathrm{Fe}$ or Ti elements in the raw sample composition in regard of the obtained pseudobrookite composition. Thus, linear curves can be plotted intercepting the abscise axis at the $\mathrm{x}$ value determining the pseudobrookite main phase composition. From these curves, the main phase composition can be extracted and was found to be $\mathrm{Fe}_{1.94} \mathrm{Ti}_{1.06} \mathrm{O}_{5}$ for $\mathrm{SA}$ samples and $\mathrm{Fe}_{1.91} \mathrm{Ti}_{1.09} \mathrm{O}_{5}$ for $\mathrm{SB}$ samples. This explains that no secondary phase was observed for the SA2 and-SB3 samples because the raw sample compositions were already very close to the main phase.

Then, we assume that, within the $\mathrm{Fe}_{2-\mathrm{x}} \mathrm{Ti}_{1+\mathrm{x}} \mathrm{O}_{5}$ solid solution, the versatility of the iron oxidation number can be tuned with the sample composition in order to obtain a pure pseudobrookite phase all along the Fe-Ti binary line. Thus, a pure monophasic phase should be obtained without any problem with a large panel of $x$ values. In most of the recent studies, ${ }^{13}$ the authors considered that the occurrence of hematite or rutile as secondary phases is due to the lack of reactivity of one of the raw binary oxide and then, they proposed to counter this phenomenon by increasing the counter-cation concentration of the target composition. Our study clearly shows that, on the contrary, the global composition has almost no influence on the chemical composition of the main phase. The pseudobrookite composition is rigidly fixed by the synthesis condition. Thus, the excess of one transition metal element ( $\mathrm{Ti}$ or $\mathrm{Fe}$ ) in regard to the defined stoichiometry has to be rejected because it initiates the germination of a binary oxide as second phase. The very low reticular energy of the pseudobrookite (positive enthalpy of formation) thermodynamically contributes without any doubt to the decomposition of the sample in one main pseudobrookite phase (with the most stable composition) and one binary oxide containing the metal in excess.

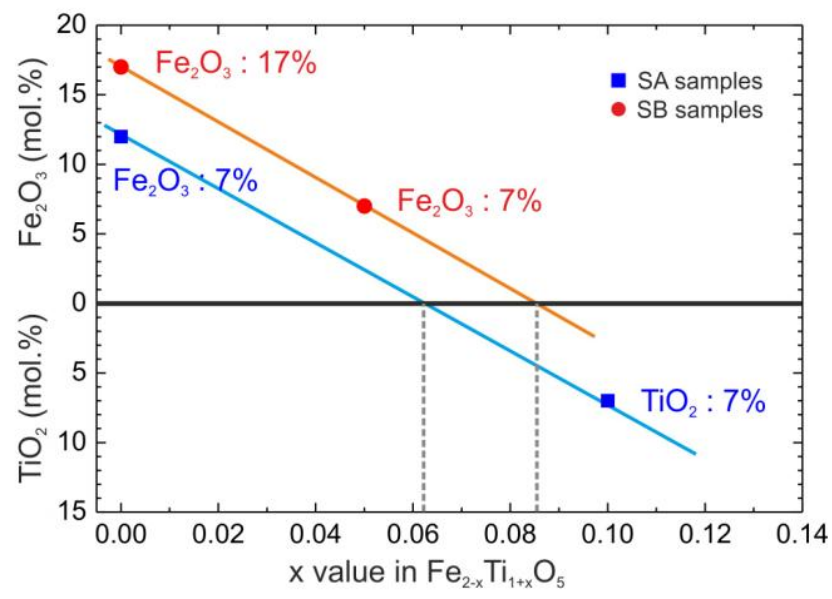

Figure 5: Molar percentage of the secondary phase versus $\mathrm{x}$ value in the $\mathrm{Fe}_{2-\mathrm{x}} \mathrm{Ti}_{1+\mathrm{x}} \mathrm{O}_{5}$ target phase obtained after thermal treatments at $900^{\circ} \mathrm{C}$ and $1400^{\circ} \mathrm{C}$.

Furthermore, the pseudobrookite phase obtained by sintering under air atmosphere has not the $\mathrm{Fe}_{2} \mathrm{TiO}_{4}$ stoichiometric composition ( $\mathrm{Fe} / \mathrm{Ti}$ ratio lower than 2) and moreover, this composition varies with the thermal treatment temperature. Two hypotheses can be formulated to explain this variation to stoichiometric composition: (i) the thermal treatment under air leads to an average oxidation number intermediate between 2 and 3 for the iron ions, (ii) the occurrence of cationic vacancies concomitantly to a dense anionic subnetwork. In the first case, the positive charge deficit induced by the occurrence of some $\mathrm{Fe}^{2+}$ species should be compensated by an excess of titanium $(\mathrm{Fe} / \mathrm{Ti}$ inferior to 2). In the second case, the cationic vacancies are responsible for positive charge defects. At first sight, the first hypothesis seems satisfactory. The $\mathrm{Fe}_{1.94} \mathrm{Ti}_{1.06} \mathrm{O}_{5}$ pseudobrookite phase obtained in the most oxidative conditions $\left(900^{\circ} \mathrm{C}\right.$ under air) should thus contain $6 \mathrm{~mol} \%$ of $\mathrm{Fe}^{2+}$ ions, while the $\mathrm{Fe}_{1.91} \mathrm{Ti}_{1.09} \mathrm{O}_{5}$ phase obtained in more reductive conditions $\left(1400^{\circ} \mathrm{C}\right.$ under air) should contain $9 \mathrm{~mol} \%$ of $\mathrm{Fe}^{2+}$ ions. In order to validate or invalidate this assumption, ${ }^{57} \mathrm{Fe}$ Mössbauer experiments were performed on SxA and SxB samples.

As an example, the room temperature ${ }^{57} \mathrm{Fe}$ Mössbauer spectrum of S2A sample can be reconstructed with two quadrupole doublets (Figure 6). Actually, a better fit to the experimental data is achieved by considering each signal as the sum of quadrupole doublets with lorentzian shape (linewidth: $0.30 \mathrm{~mm} / \mathrm{s}$ ), same isomer shift but different quadrupole splitting values (ie. with a "distribution of quadrupole splitting values"). The hyperfine parameters reported in Table 5, isomer shift (about $0.38 \mathrm{~mm} / \mathrm{s}$ ) 
and quadrupole splitting $(0.5<<\Delta><1.0 \mathrm{~mm} / \mathrm{s})$, are characteristic of trivalent iron ions in octahedral environment. Regarding the previous results of Rietveld structural refinements from XRD data and the relative proportion of these two signals (about 40:60), the "doublet" with the highest mean value of quadrupole splitting $(<\Delta>=0.94 \mathrm{~mm} / \mathrm{s})$ can be associated to $\mathrm{Fe}^{3+}$ ions located at the $4 c$ Wyckoff position and the other one, with $<\Delta>=0.55 \mathrm{~mm} / \mathrm{s}$, to iron ions at the $8 f$ site within the pseudobrookite structure. Moreover, no significant amount of divalent iron was detected at room temperature.

\section{velocity $(\mathrm{mm} / \mathrm{s})$}
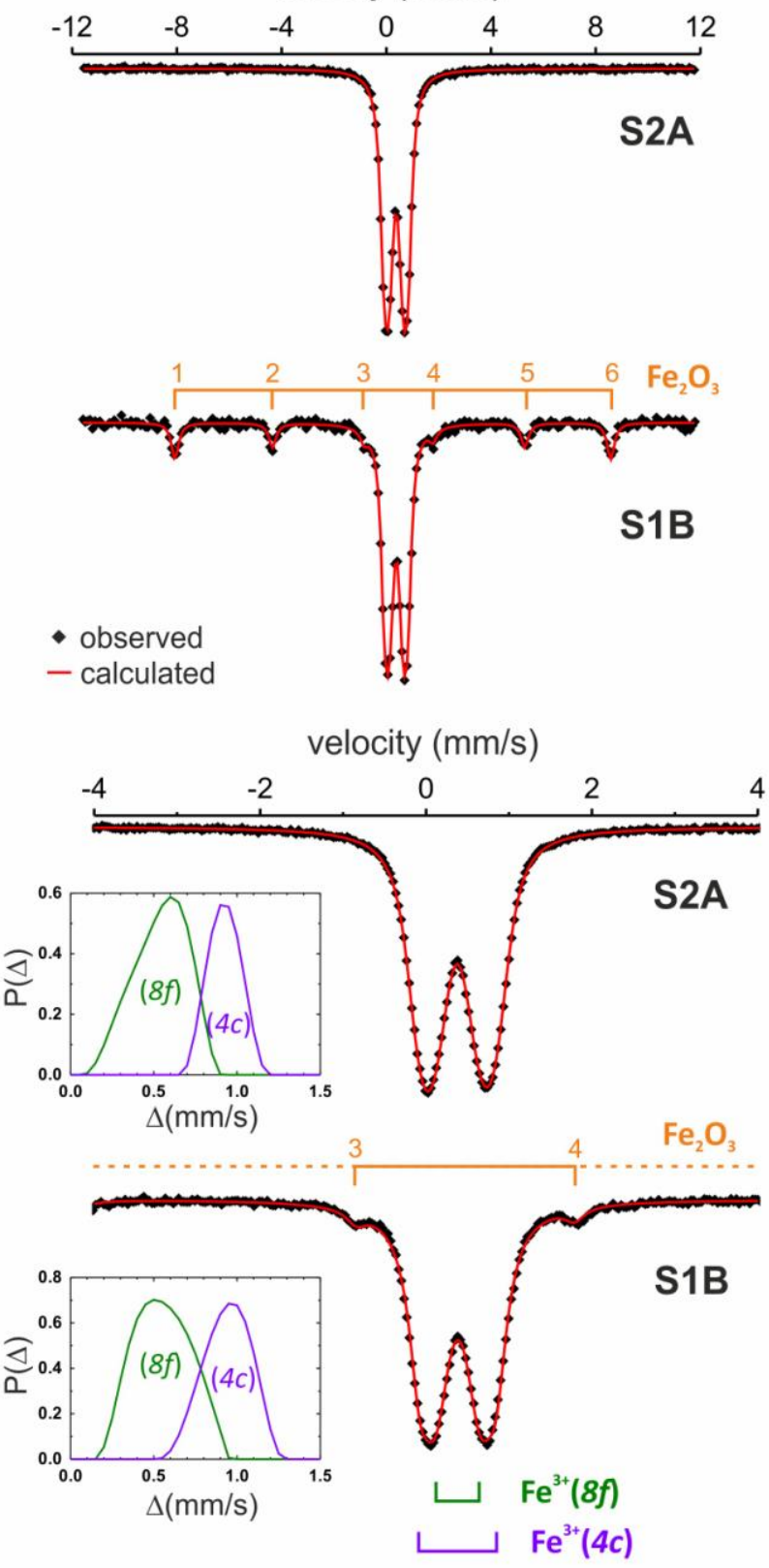

Figure 6: Room temperature ${ }^{57}$ Fe Mössbauer spectra of S2A and S1B samples. High velocity measurements undoubtedly reveal the presence of hematite for S1B. Insets: Distributions of quadrupole splitting.

Considering that $\mathrm{Fe}^{3+}$ is in a high-spin state and that the ${ }^{6} \mathrm{~S}$ ground state has a spherically symmetric distribution of electronic charge, the quadrupole splitting arises mainly from the lattice contribution to the electric field gradient (EFG) through the crystal field produced by ligands and first-neighbor cations at the ${ }^{57} \mathrm{Fe}$ nucleus. Then, a distribution of quadrupole splitting may reflect slight variations of the EFG due to some local disorder or heterogeneity in site distortion, for example. Thus, the values of quadrupole splitting observed for the two $\mathrm{Fe}^{3+}$ signatures indicate that the two associated sites present different degrees of distortion, which may be influenced by the cationic network and the possible occurrence of cationic vacancies in the second coordination sphere of iron ions.

TABLE 5. ${ }^{57}$ Fe Mössbauer parameters determined from the fitting of $\mathrm{SxA}$ and $\mathrm{SxB}$ spectra. *mean value of quadrupole splitting distribution.

\begin{tabular}{|c|c|c|c|c|c|c|}
\hline & $\begin{array}{c}\delta \\
(\mathrm{mm} / \mathrm{s})\end{array}$ & $\begin{array}{c}<>^{*} \\
(\mathrm{~mm} / \mathrm{s})\end{array}$ & $\begin{array}{c}\varepsilon \\
(\mathrm{mm} / \mathrm{s})\end{array}$ & $\begin{array}{l}\mathrm{H} \\
(\mathrm{T})\end{array}$ & $\begin{array}{c}\Gamma \\
(\mathrm{mm} / \mathrm{s})\end{array}$ & $\begin{array}{l}\text { area } \\
(\%)\end{array}$ \\
\hline \multicolumn{7}{|l|}{ S1A } \\
\hline $\mathrm{Fe}^{3+}(8 f)$ & 0.378 & 0.57 & - & - & 0.30 & 54 \\
\hline $\mathrm{Fe}^{3+}(4 c)$ & 0.381 & 0.95 & - & - & 0.30 & 33 \\
\hline $\mathrm{Fe}_{2} \mathrm{O}_{3}$ & 0.369 & - & -0.23 & 51.5 & 0.31 & 13 \\
\hline \multicolumn{7}{|l|}{ S2A } \\
\hline $\mathrm{Fe}^{3+}(4 c)$ & 0.381 & 0.94 & - & - & 0.30 & 43 \\
\hline \\
\hline $\mathrm{Fe}^{3+}(4 c)$ & 0.382 & 0.97 & - & - & 0.30 & 36 \\
\hline \multicolumn{7}{|l|}{ S1B } \\
\hline $\mathrm{Fe}^{3+}(4 c)$ & $\begin{array}{l}0.382 \\
0.384\end{array}$ & $\begin{array}{l}0.54 \\
0.92\end{array}$ & - & - & $\begin{array}{l}0.30 \\
0.30\end{array}$ & $\begin{array}{l}52 \\
30\end{array}$ \\
\hline $\mathrm{Fe}_{2} \mathrm{O}_{3}$ & 0.365 & - & -0.22 & 51.6 & 0.33 & 18 \\
\hline \multicolumn{7}{|l|}{ S2B } \\
\hline $\mathrm{Fe}^{3+}(4 c)$ & 0.387 & 0.91 & - & - & 0.30 & 36 \\
\hline $\mathrm{Fe}_{2} \mathrm{O}_{3}$ & 0.368 & - & -0.18 & 51.5 & 0.31 & 5 \\
\hline \multicolumn{7}{|l|}{ S3B } \\
\hline $\mathrm{Fe}^{3+}(8 f)$ & 0.381 & 0.50 & - & - & 0.30 & 57 \\
\hline $\mathrm{Fe}^{3+}(4 c)$ & 0.380 & 0.91 & - & - & 0.30 & 43 \\
\hline
\end{tabular}

In addition to the $\mathrm{Fe}^{3+}(4 c)$ and $\mathrm{Fe}^{3+}(8 f)$ signals, three samples exhibit a magnetic component (sextet) whose hyperfine parameters are characteristic of hematite $\left(\mathrm{Fe}_{2} \mathrm{O}_{3}\right)$ (Figure 6 and Table 5). From the analysis of high velocity spectra, the amount of this secondary phase was estimated to 5, 13 and $18 \%$ (molar percentage) for S2B, S1A and S1B samples, respectively. These results are in good agreement with the amounts of hematite determined from XRD analyses (7, 12 and $17 \%$, respectively).

The Mössbauer analysis of the S3B sample at various temperatures down to $4.2 \mathrm{~K}$ (Figure 7) reveals (i) at $100 \mathrm{~K}$ the presence of a very weak signal (less than $1 \%$ ) which may be associated with $\mathrm{Fe}^{2+}$ ions (probably located at the surface) and (ii) the beginning of a magnetic ordering at a temperature close to 50 K. Different Lamb-Mössbauer-factors $f$ (between $\mathrm{Fe}^{3+}$ and $\mathrm{Fe}^{2+}$ species) could explain that the $\mathrm{Fe}^{2+}$ signal is not observed at room temperature but only below $100 \mathrm{~K}$. At $4.2 \mathrm{~K}$ the pseudobrookite phase is fully magnetically ordered, and the spectra can be well fitted considering two sextuplets (with hyperfine field distributions), i.e. the occurrence of two different $\mathrm{Fe}^{3+}$ species corresponding to the cation distribution into the $4 c$ and $8 f$ sites. At this temperature the contribution of the $\mathrm{Fe}^{2+}$ signature (sextet) is negligible and hardly quantifiable. For the S3B sample, all the 
parameters refined for the fitting of the Mössbauer spectra recorded at 293, 100, 50 and $4.2 \mathrm{~K}$ are summed-up in the Table 6.

Hence, the Mössbauer study performed on the S2A and S3B samples, constituted by a single pseudobrookite phase, strongly suggests that the crystallization of a pure pseudobrookite phase from iron deficient chemical compositions $(\mathrm{Fe} / \mathrm{Ti}<2)$ is not due to the stabilization of $\mathrm{Fe}^{2+}$ into the bulk but to the occurrence of cationic vacancies.
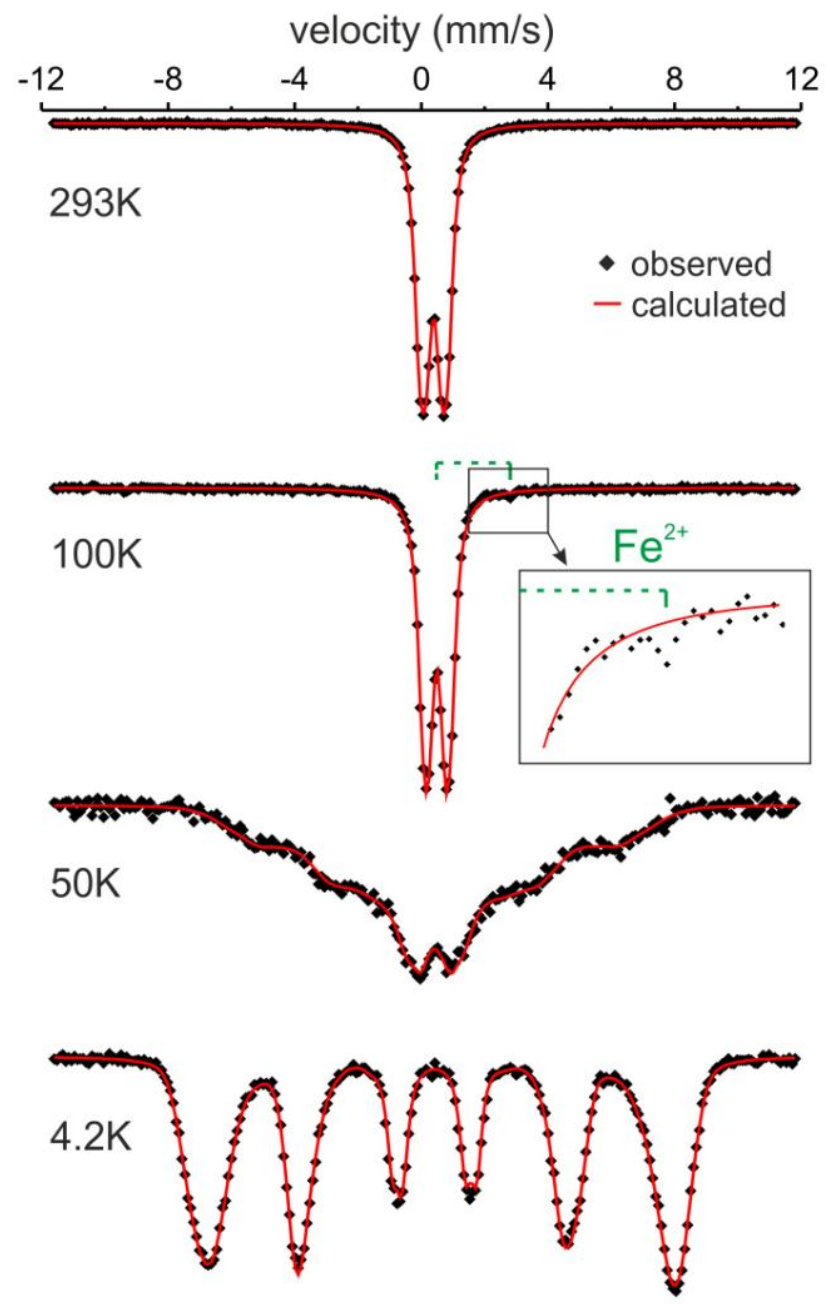

Figure 7: ${ }^{57} \mathrm{Fe}$ Mössbauer spectra of S3B sample recorded from room temperature down to $4.2 \mathrm{~K}$.

The formulae of the oxide should so include cationic vacancies. A proposed formulation can be written as $\left(\mathrm{Fe}^{3+}{ }_{2-\mathrm{x}} \mathrm{Ti}^{4+}{ }_{1+\mathrm{x}}\right)_{1-\mathrm{z}} \mathrm{V}_{\mathrm{z}} \mathrm{O}_{5}$, the electroneutrality of the composition leading to a vacancy concentration: $\mathrm{z}=\mathrm{x} /(\mathrm{x}+10)$. This hypothesis of $\mathrm{z}$ vacancy concentration fixed by the synthesis process is the only way to explain the formation of hematite or rutile secondary phase in various quantities depending on the thermal treatment temperature. The calculation of the $\mathrm{z}$ value form the composition of the sample and the concentration of hematite or rutile phase as impurities leads to $\mathrm{z} \sim 0.006(\mathrm{x} \sim 0.06)$ and $\mathrm{z} \sim 0.0009(\mathrm{x} \sim 0.09)$ for the SxA and SxB samples, respectively. Thus, the vacancy concentration increases with the thermal treatment temperature, i.e. versus the crystallite size. This clearly shows that the considered vacancies are located inside the material bulk and not on the material surfaces.
The last part of the study is devoted to the optical properties characterization. The diffuse reflectance curves recorded on the 6 studied samples are reported in the Figure 8. The colorimetric parameters in $\mathrm{L}^{*} \mathrm{a}^{*} \mathrm{~b}^{*}$ space extracted from the diffuse reflectance curves as well as the color of each powder are joined in the Figure 9.

TABLE 6. ${ }^{57} \mathrm{Fe}$ Mössbauer parameters determined from the fitting of S3B spectra recorded at various temperatures (Figure 7). *mean value of quadrupole splitting or hyperfine field distribution.

\begin{tabular}{|lcccccc|}
\hline $\mathrm{S} 3 \mathrm{~B}$ & $\begin{array}{c}\delta \\
(\mathrm{mm} / \mathrm{s})\end{array}$ & $\begin{array}{c}<\Delta>^{*} \\
(\mathrm{~mm} / \mathrm{s})\end{array}$ & $\begin{array}{c}\varepsilon \\
(\mathrm{mm} / \mathrm{s})\end{array}$ & $\begin{array}{c}<\mathrm{H}>^{*} \\
(\mathrm{~T})\end{array}$ & $\begin{array}{c}\Gamma \\
(\mathrm{mm} / \mathrm{s})\end{array}$ & $\begin{array}{c}\text { area } \\
(\%)\end{array}$ \\
\hline $\mathbf{2 9 3} \mathbf{K}$ & & & & & & \\
$\mathrm{Fe}^{3+}(8 \mathrm{f})$ & 0.38 & 0.50 & - & - & 0.30 & 57 \\
$\mathrm{Fe}^{3+}(4 \mathrm{c})$ & 0.38 & 0.91 & - & - & 0.30 & 43 \\
\hline $\mathbf{1 0 0 ~ K}$ & & & & & & \\
$\mathrm{Fe}^{3+}(8 f)$ & 0.48 & 0.52 & - & - & 0.30 & 60 \\
$\mathrm{Fe}^{3+}(4 c)$ & 0.48 & 0.90 & - & - & 0.30 & 40 \\
\hline $\mathbf{5 0 ~ K}$ & & & & & & \\
$\mathrm{Fe}(1)$ & 0.49 & - & 0.37 & 20.9 & 0.35 & 62 \\
$\mathrm{Fe}^{2}(2)$ & 0.49 & - & -0.09 & 21.2 & 0.35 & 38 \\
\hline $\mathbf{4 . 2 ~ K}$ & & & & & & \\
$\mathrm{Fe}^{3+}(8 f)$ & 0.50 & - & 0.51 & 44.6 & 0.35 & 57 \\
$\mathrm{Fe}^{3+}(4 c)$ & 0.49 & - & -0.11 & 44.4 & 0.35 & 43 \\
\hline
\end{tabular}

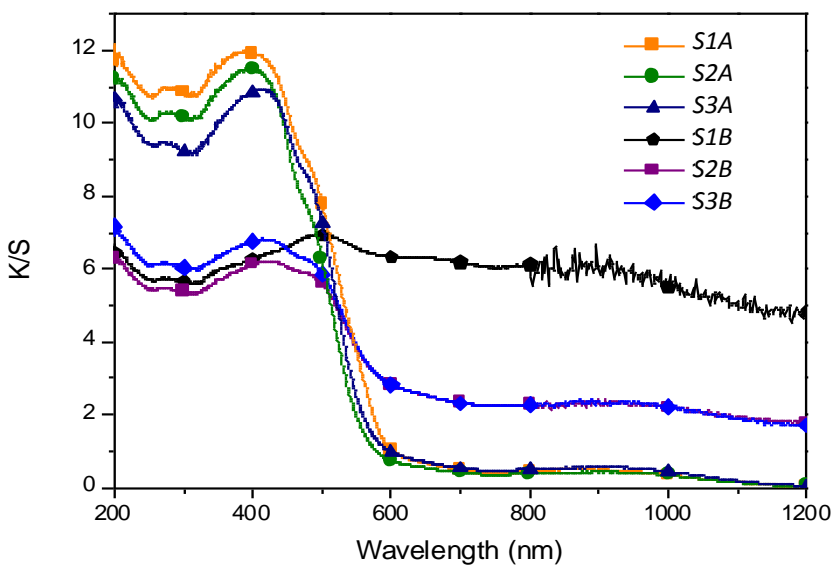

Figure 8: K/S Kubelka-Munk transform obtained from diffuse reflectance spectra recorded on the six reference samples.

The diffuse reflectance curves show for all the samples a main gap at about $600 \mathrm{~nm}$. This optical gap can reasonably indexed as a charge transfer between oxygen and $\mathrm{Fe}^{3+}$ ions. Indeed, a quite similar gap energy is observed for $\mathrm{Fe}_{2} \mathrm{O}_{3}$ hematite compounds in which $\mathrm{Fe}^{3+}$ ions are also located in octahedral sites while $\mathrm{TiO}_{2}$ exhibits a $\mathrm{O}^{2-} \rightarrow \mathrm{Ti}^{4+}$ gap in the near UV domain. Hence, for all the six samples, in first approximation, it can be assumed than the color variation is the consequence of the composition variation of the main phase. But to be absolutely rigorous, it cannot be neglected that the traces of the secondary phases slightly impact the compound color. For the three samples obtained at low temperature, this optical gap is the only contribution to the reflectance curves. But, for the three samples obtained at $1400^{\circ} \mathrm{C}$, a very large absorptive contribution in the visible domain can also be noticed. The consequence of this large absorption is the $\mathrm{SxB}$ samples are both brown whereas the SxA samples were ochre. Obviously, basing on the physico-chemical characterization 
already discussed all along this paper, it is clear that the cationic vacancies evidenced by Mossbauer spectroscopy, especially with higher concentration in the $\mathrm{SxB}$ samples, can be at the origin of the slightly intense and large absorptive contribution in the visible part of the spectrum. On an applicative point of view, these characterizations shows that it is a challenge to accurately control the colorimetric parameters of ferric pseudobrookite for their use as inorganic pigments into ceramic or refractory materials. The coloration depends indeed strongly on the thermal history of the pigments.
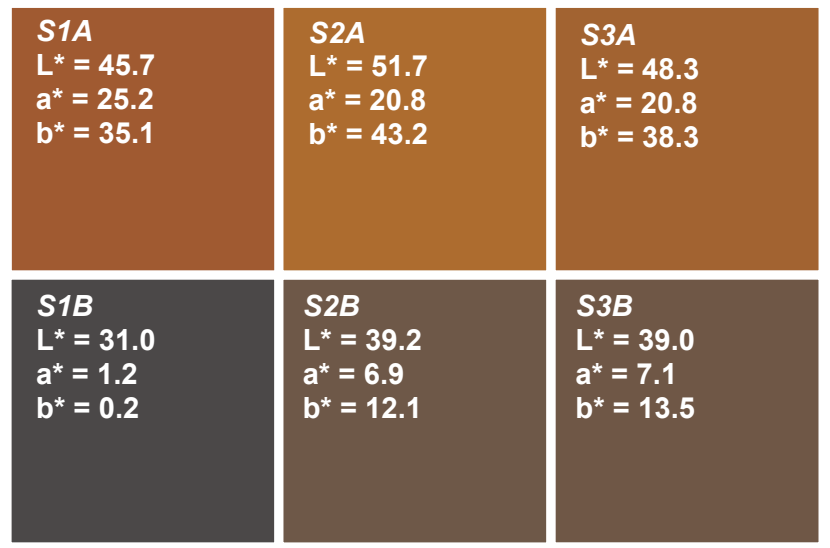

Figure 9: $\mathrm{L}^{*} \mathrm{a} * \mathrm{~b} *$ three color-space parameters extracted from the $\mathrm{K} / \mathrm{S}$ spectra for the six reference samples.

\section{Conclusion.}

Pseudobrookite solid solutions with $\mathrm{Fe}_{2-\mathrm{x}} \mathrm{Ti}_{1+\mathrm{x}} \mathrm{O}_{5}$ composition $(\mathrm{x}=0,0.05$ and 0.10$)$ have been successfully prepared by the Pechini route and thereafter, thermally treated at $900^{\circ} \mathrm{C}$ or $1400^{\circ} \mathrm{C}$. Thus, six different samples (three compositions, two thermal histories) can be compared to further discuss the formation of $\mathrm{Fe}_{2} \mathrm{O}_{3}$ or $\mathrm{TiO}_{2}$ secondary phases, the occurrence or not of $\mathrm{Fe}^{2+}$ ions and consequent structural modifications.

The main deductions arising from this study based on various coupled techniques: ${ }^{57} \mathrm{Fe}$ Mössbauer spectroscopy, X-ray diffraction, scanning electron microscopy and optical spectroscopy are the following:

(i) Both composition and thermal history had an important effect on the occurrence of secondary phases in addition to the main pseudobrookite one. The investigation into the properties of these compounds is then complex but essential to consider the use of iron-rich pseudobrookite as ceramic pigments. Stoichiometric $\mathrm{Fe}_{2} \mathrm{TiO}_{5}$ phases cannot be obtained without any traces of $\mathrm{Fe}_{2} \mathrm{O}_{3}$ oxide. The moderate increase of the titanium concentration allowed us to obtain a pure solid solution (with an adequate thermal treatment). A more important increase of the titanium concentration leads to the formation of rutile as secondary phase.

(ii) The crystal structure was investigated from accurate analyses of X-ray diffraction pattern and ${ }^{57} \mathrm{Fe}$ Mössbauer signal. An almost statistical distribution of $\mathrm{Fe}^{3+} / \mathrm{Ti}^{4+}$ ions in the two cationic sites (4c / $8 f$ Wyckoff positions) was evidenced with a slight but significant preference of the iron ions for the $4 c$ sites. Furthermore, the relative cationic distribution is slightly but significantly influenced by chemical composition and thermal history. These results are in good agreement with previous published works. ${ }^{13-17}$ (iii) Whatever the composition and the thermal history, almost all iron ions are at the +III oxidation state as revealed by Mössbauer spectroscopy. Thus, the charge compensation mechanism associated with the $\mathrm{Fe}^{3+}$ for $\mathrm{Ti}^{4+}$ ions substitution (in order to maintain the electroneutrality) is not achieved by the equivalent reduction of $\mathrm{Fe}^{3+}$ to $\mathrm{Fe}^{2+}$ species, even if the presence of an infinitesimal amount of $\mathrm{Fe}^{2+}$ cannot be definitely excluded.

(iv) Both thermal history and composition, but especially the thermal history, impact the optical properties. The formation of hematite or rutile as secondary phase may thus be related to the occurrence of cationic vacancies within the pseudobrookite structure, the amount of vacancies depending on the annealing temperature. In the light of the presented results, it appears unreasonable to propose a "fixed" binary phase diagram for such a complex system. Furthermore, the occurrence of cationic vacancies induces a coloration change (darkening), preventing any industrial use of this reddish-brown pseudobrookite as ceramic pigment.

These four observations can only be completely interpreted considering that the iron-rich pseudobrookite compounds exhibit cationic vacancies, more precisely a cation:anion ratio lower than $3: 4$ (theoretical formulae ratio). Then, only $\mathrm{Fe}^{3+}: \mathrm{Ti}^{4+}$ ratios slightly superior to 2 leads to the obtaining of a pure pseudobrookite. The cationic vacancies concentration is notably impacted by the thermal history, explaining then the influence of thermal treatment temperature on the secondary phase concentrations. As the thermal treatment temperature increases, the occurrence of rutile secondary phase is clearly favored, to the detriment of those of hematite secondary phase. It can thus be deduced that the cationic vacancies concentration decreases versus the treatment temperature. Moreover, the crystallization degree, clearly revealed by SEM images, appears to be related to the stoichiometry of the main pseudobrookite phase. Then, the cation/anion ratio may be influenced by an anionic overstoichiometry at the crystal surface.

Finally, the "ochre" color of pseudobrookite could be interesting for pigment manufactories but its sensitivity to the thermal history of the compound (and also to the oxygen partial pressure, so far, a research axis which is not investigated) implies that the synthesis process has to be perfectly controlled.

\section{Acknowledgement.}

The authors wish to gratefully acknowledge Philippe Sciau and Mickaël Dollé from CEMES-CNRS (Toulouse - France). P.S. has been deeply studying Ancient Roman Ceramics using several technics such as Transmission Electron Microscopy, X-ray micro spectroscopies and micro diffraction, in order to correlate (i) color aspect and (i) the elemental and mineralogical phase distributions. $\mathrm{Fe}_{2} \mathrm{TiO}_{5}$ have been identified to be responsible of the yellowish color in the "marbled terra sigillata". It is for this reason that we focused our attention on the specific study of this compound.

\section{AUTHOR INFORMATION}

\section{Corresponding Author}

Email: gaudon@icmcb-bordeaux.cnrs.fr

\section{Author Contributions}

The manuscript was written through contributions of all authors. All authors have given approval to the final version of the manuscript. 


\section{Notes}

The authors declare no competing financial interests.

\section{REFERENCES}

(1) Taylor, R.W. Am. Mineral. 1964, 49, 1016-1030.

(2) Ishikawa, Y. J. Phys. Soc. Jpn. 1957, 12, 1083-1098.

(3) Hamelin, M. Bull. Soc. Chim. France 1958, 67, 1559-1566.

(4) Pauling, L. Kristallor. 1930, 73, 97-112.

(5) Akimoto, S.; Nagat, T.; Katsura, T. Nature, 1957, 179, 37.

(6) Wyckoff, R.W.G.; Crystal Structures, John Wiley: New York, 1963.

(7) Lind, M.D.; Housley R.M. Science 1972, 175, 521-523.

(8) Shirane, G.; Cox, D.E.; Ruby, S.L. Phys. Rev. 1962, 125, 11581165 .

(9) Muranaka, S.; Shinjo, T.; Bando, Y.; Takada, T. J. Phys. Soc. Jpn. 1971, 30, 890

(10) Gurewitz, E.; Atzmony, U. Phys. Rev. B 1982, 26 6093-6098.

(11) Cruz, J.M.R.; Morais, P.C.; Neto, K.S. Phys. Lett. A 1986, 116, 45-47.

(12) Grey, I.E.; Ward, J. J. Solid State Chem. 1973, 7, 300-307

(13) Guo W.Q.; Malus, S.; Ryan, D.H.; Altounian, Z. J. Phys.: Condens. Matter 1999, 11, 6337-6346.

(14) Enhessari, M.; Kargar Razi M.; Etemad, L.; Parviz, A.; Sakhaei, M. J. Exp. Nanosc. 2012, 9, 167-176.

(15) Khaleel, A. Colloids Surf. A: Physicochem. Eng. Aspects. 2009, 346, 130-137. 132.

(16) Kozuka, H.; Kajimura, M., J. Sol-Gel Sci. Technol. 2001, 22, 125-

(17) Prasad, N.V.; Srinivas, K.; Kumar, G.S.; James, A.R. Appl. Phys. A: Mater. Sci. Process, 2001, 72, 341-345.

(18) Toby, H.; J. Appl. Crystallogr. 2001, 34, 210-213.

(19) Rademachers, J.; Erfuth, H.; Hund, F. U.S. Patent 4,036,662, 1977.

(20) Hund, F.; Holznagel, W.; Erfuth, H.; Kindervater, F.; Hennings, W. U.S. Patent 4,084,984, 1978.

(21) Dondi, M.; Matteucci, F.; Cruciani, G.; Gasparotto, G.; Tobaldi, D.M. Solid State Sci. 2007, 9, 362-369.

(22) Maloney, J.; High Performance Pigments, Wiley-VCH, Weinheim, 2002.

(23) Momma, K.; Izumi, F. J. Appl. Crystallogr. 2011, 44, 1272-1276.

(24) Bayer, G. J. Less-Common Metals, 1971, 24, 129-138.

(25) Navrotsky, A. Am. Mineral. 1975, 60, 249-256.

(26) Pechini, M.P. U.S. Patent 3,3306,97. 1967.

(27) Tai, L.W.; Lessing P.A. J. Mater. Res. 1992, 7, 502-510.

(28) Tai L.W., Lessing P.A. J. Mater. Res. 1992, 7, 511-519.

(29) Rietveld, H.M. Acta Crystallogr. 1967, 22, 151-152.

(30) Rietveld, H.M. J. Appl. Crystallogr., 1969, 2, 65-71 
For Table of Contents Only

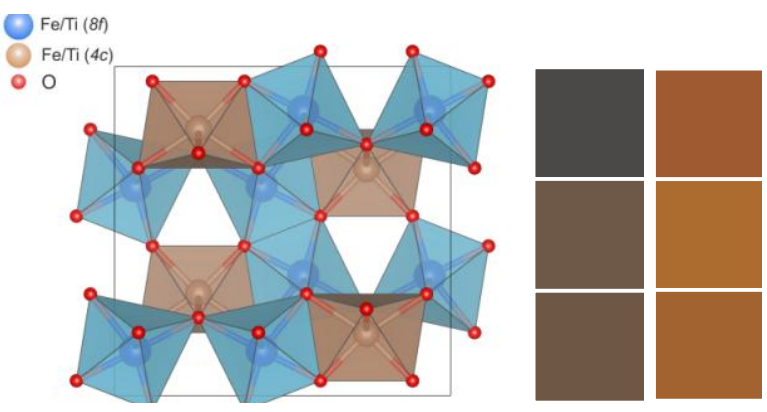

Iron-rich pseudobrookite solid solutions with $\mathrm{Fe}_{2-\mathrm{x}} \mathrm{Ti}_{1+\mathrm{x}} \mathrm{O}_{5}$ composition were studied using Mössbauer spectroscopy, X-ray diffraction, scanning electron microscopy and optical spectroscopy. Both thermal history and composition impact the optical properties. The phenomenon can only be interpreted considering that the iron-rich pseudobrookite compounds exhibit cationic vacancies. In view of pigment applications, a large palette of ochres can so be obtained using a perfectly controlled synthesis process. 